\title{
A práxis reflexiva das relações públicas no contexto da sociedade midiatizada: uma proposta teórico-prática para o ensino em ambiências digitais
}

\section{The reflective praxis of public relations in the context of mediatized society: a theoretical and practical proposal for education in digital ambiences}

\author{
Elisângela Lasta \\ Doutora em Comunicação pela Universidade Federal de Santa Maria (UFSM), professora do Departamento de Comunicação \\ Faculdade de Biblioteconomia e Comunicação - da Universidade Federal do Rio Grande do Sul (UFRGS). Atua nas áreas de \\ comunicação digital e relações públicas digitais. \\ <elisangela.lasta@gmail.com>
}

\section{Eugênia Maria Mariano da Rocha Barichello}

Doutora em Comunicação pela Universidade Federal do Rio de Janeiro (UFRJ), docente permanente do Programa de PósGraduação em Comunicação da Universidade Federal de Santa Maria (UFSM). Estágio Pós-doutoral Sênior na University College of London (UCL-UK), com bolsa da Coordenação de Aperfeiçoamento de Pessoal de Nível Superior - CAPES (BEX 2384/14-0). <eugeniabarichello@gmail.com>

\section{RESUMO}

O problema desta pesquisa está ancorado no pressuposto de que o atual contexto da sociedade midiatizada movimenta os conceitos relativos à práxis das relações públicas. O objetivo é apresentar uma proposta para o ensino das relações públicas em ambiências digitais baseada em seis itens: $1^{\circ}$ ) identificação do objetivo; $2^{\circ}$ ) exame crítico das práticas; $3^{\circ}$ ) busca de explicações e de alternativas; $\left.4^{\circ}\right)$ experimentação de modos alternativos de fazer; $\left.5^{\circ}\right)$ revisão das estratégias; $\left.6^{\circ}\right)$ realização de novas experiências e reflexões. A metodologia inclui pesquisa empírica e os resultados levam a ponderar a íntima relação entre a teoria e o empírico e a pensar esse ensino sob um ciclo recursivo.

Palavras-chave: Relações públicas. Sociedade midiatizada. Ambiências digitais.

\begin{abstract}
The problem of this research is grounded on the assumption that the current context of mediatized society moves the concepts related to the practice of public relations. The objective is to present a proposal for the teaching of public relations in digital ambiences based on six items: 1st identification of the objective; 2 nd critical examination of the practices; 3 rd the search for explanations and alternatives; 4th trial of alternative ways of doing; 5 th review of the strategies; 6th realization of new experiences and reflections. The methodology includes empirical research and the results lead to consider the close relationship between theory and empirical and to think this teaching in a recursive cycle.
\end{abstract}

Keywords: Public relations. Mediatized society. Digital ambiences.

\section{Introdução}

A práxis das relações públicas, no contexto da sociedade midiatizada, está 
sustentada no fazer, no existir e no representar das organizações ${ }^{1}$, e também no saber "dizer/publicizar" relativos aos processos de "explicar" e "justificar" suas ações, ressaltando que esta dinâmica está articulada "nos" e "pelos" media digitais.

Essa proposta processual implica em dois movimentos: o primeiro é a construção de si para o outro; o segundo, a exteriorização da subjetividade por meio de processos comunicacionais. Abrange, portanto, a interpretação crítica "nas" e "das" relações entre organizações e públicos, e inclui os processos comunicacionais, oficiais ou formais e não oficiais ou informais, na estrutura da $W e b^{2}$. Esses pressupostos nos levam a refletir sobre a educação dos profissionais de relações públicas na sociedade midiatizada, pois esses profissionais costumam intuir por experiências continuadas. Porém, o processo quando puramente empírico não reflete sobre as práticas de relacionamento na contemporaneidade e seus desafios atuais.

O processo de midiatização da sociedade requer considerarmos o saber comunicacional, pensado por meio da redescrição dessa realidade considerando a ordem tecnológica e as renovadas experiências do indivíduo em seu relacionamento, que se dá a partir do agenciamento com dispositivos sociotécnicos, em ambiências digitais. A partir desse pressuposto, propomos que o ensino das relações públicas esteja baseado no raciocínio que considera seis elementos: $1^{\circ}$ ) identificação do objetivo; $2^{\circ}$ ) exame crítico das práticas; $3^{\circ}$ ) busca de explicações e de alternativas para as práticas; $4^{\circ}$ ) experimentação de modos alternativos de se fazer (prática); $5^{\circ}$ ) revisão das estratégias empregadas; $\left.6^{\circ}\right)$ realização de novas experiências e reflexão. Este processo permite pensar o ensino sob um ciclo recursivo que comporte a compreensão da práxis das relações públicas neste contexto por meio do uso e apropriação das ambiências digitais como mediação estratégica comunicacional.

O artigo está subdivido em duas partes: a primeira aborda o contexto da sociedade midiatizada; a segunda apresenta o ciclo recursivo que sustenta a proposta do ensino das relações públicas em ambiências digitais.

1 Compreendemos por organização a instituição concretizada, onde as práticas institucionalizadas são condicionadas a normas em busca de um objetivo comum.

2 Estes processos desdobram-se nas ambiências da web e são indexáveis pelos buscadores. A partir do reconhecimento dessa conjuntura nossa proposta é de que a organização necessita-se fazer visível aos motores de busca. Ver Lasta (2015). 


\section{O contexto: sociedade midiatizada}

O contexto da sociedade midiatizada pode ser visualizado a partir do reconhecimento da alteridade dos atores nos processos comunicacionais estabelecidos em ambiências digitais. Conceitualmente, esse contexto é apreendido na articulação entre a ambiência e a vivência nos media digitais, processo no qual os sujeitos individuais e coletivos se agenciam e se constroem.

Este estudo considera o domínio do conhecimento referente às ambiências digitais; os processos comunicacionais; e a arquitetura estrutural da web. Tendo em vista que a comunicação digital se dá por meio de um processo sócio-técnico-discursivo, no qual o sócio é representado pelo reconhecimento de outrem ${ }^{3}$ (relação possível); o técnico, pelos códigos e estruturas próprias a cada ambiência digital (domínio do conhecimento); e o discursivo pela retórica e elocução nessas ambiências (processo comunicacional). Consequentemente, esse processo nos remete a duas dimensões: a dimensão individual e a dimensão relacional.

A dimensão individual (ator e ambiência) é relativa ao agenciamento do ator com a ambiência digital (que possui códigos e estruturas próprias). Equivale à construção de sua representação no seu espaço. Nessa primeira dimensão encontramos a proposta da ambiência digital como mediação, seu "espaço/ lugar de fala/atuação" e de proposição de inter-relações. Isto é, operação em que uma ambiência une duas realidades - o entre/o que liga/o elo - (Domingues, 2010), visando fazer ponte ou fazer comunicar duas partes (Sodré, 2009); logo, descreve o ato concreto da comunicação (Hjarvard, 2012). Contudo, como salienta Braga (2012), a mediação comunicacional, na contemporaneidade, varia de acordo com o elemento mediador (media digitais), os sujeitos e os modos de atuação. Essas ambiências estão contidas na estrutura da web ${ }^{4}$, funcionam atreladas aos buscadores e esses, por sua vez, aos indivíduos. Além disso, há dois fatores determinantes para classificação da posição dos ambientes digitais na web: palavras-chave na ambiência e sua frequência; e qualidade e quantidade de links internos e externos (Felipini, 2010).

3 O conceito de outrem parte da lógica do outro "percebido"; entretanto, como experiência de um "eu" em composição com a experiência do outro. Por meio do (seu) saber e (seu) querer, reconhece esse, visando ser-com e/ou ser-entre, como aquele do qual nos aproximamos (Ricoeur, 2006).

4 Na parte central da estrutura, encontram-se as ambiências que se referenciam mutuamente. No lado oposto, encontram-se as ambiências solitárias, que não referenciam outras e também não são referenciadas. E nas laterais encontram-se as ambiências que referenciam outras, grupo IN, porém são pouco referenciadas e, no grupo OUT, estão as que são amplamente referenciadas por outras, mas não referenciam. 
Em primeiro lugar, consideramos, neste estudo, a posição dos atores no ambiente digital, pois os serviços de busca ainda atrelam seus resultados diretamente às palavras-chave e, consequentemente, o levantamento de palavras-chave relacionadas ao assunto torna-se essencial e contempla a geração de um fluxo qualificado de palavras-chave. Após a realização desse levantamento, a próxima etapa consiste na localização do primeiro fator determinante, ou seja, as palavras-chave presentes e também a verificação da frequência das mesmas na ambiência em estudo. Já, o segundo fator determinante é a qualidade e quantidade de links, ou seja, trata-se de uma espécie de reconhecimento da qualidade da ambiência por outrem. Esse processo de reconhecimento dá-se por meio do PageRank do Google, que possui um mecanismo de valoração/ relevância das ambiências, com algoritmos que consideram se o medium digital é referenciado por outros que, por sua vez, são também referenciados por outros (Oliveira, 2010). A fórmula considera:

- links de entrada: correspondem aos links recebidos de outros e quanto mais receber esse tipo de link, melhor será o PageRank. Porém, o link de entrada poderá ser "penalizado" pelo serviço de busca caso seja considerado que os links foram realizados sem critérios, somente com o intuito de obter quantidade e não qualidade.

-links de saída: correspondem aos links realizados e possuem uma divergência em relação ao seu funcionamento. Pois, nessa ação pode ocorrer perda na pontuação do PageRank, entretanto esse tipo de link torna-se fundamental no que se refere aos relacionamentos e à busca por reciprocidade de links, ou seja, pela referenciação;

- links internos: correspondem aos links entre ambiências do mesmo domínio. Esses tipos de links afetam a distribuição da pontuação entre as ambiências; logo, a ambiência com maior número de links terá proporção maior no PageRank, pois esse entenderá que ela é a principal.

Em segundo lugar, consideramos a dimensão relacional, que se refere ao agenciamento do ator com a ambiência e, posteriormente, a inter-relação com outro ator-ambiência. Essa dimensão processual corresponde à construção de relações e/ou vínculos por meio da retórica e locução na ambiência (processo comunicacional sócio-técnico-discursivo). Na segunda dimensão nos deparamos com o processo comunicacional relacionado à interpretação dos fenômenos constituídos pela tecnologia.

Neste estudo a estratégia comunicacional é considerada por meio da articulação de pensamentos sobre o processo estratégico formulado pelos teóricos Landowski (1992), Baldissera (2001) e Pérez (2001, 2012). Nesse 
processo, o ator primeiro reconhece outrem; posteriormente constrói o simulacro desse; para então construir a situação de referência e promover o fazer estratégico por meio do ato enuncivo e do discurso enunciado (Landowski, 1992). Esse constructo funciona a partir do plano dos interlocutores, baseado em informações e conhecimentos prévios no processo de construção e disputa de sentidos (Baldissera, 2001), logo o outro passa a ser reconhecido como articulador e estrategista (Pérez, 2012). Portanto, ocorre a partir da seguinte dinâmica:

Em primeiro lugar, há o reconhecimento de outrem: ocorre quando a presença do outro é percebida e sua rede de comunicação e relações compreendidas (Landowski, 1992), ou seja, outrem como interlocutor (Baldissera, 2001) e considerado como articulador e estrategista também (Pérez, 2012).

Em segundo, a construção do simulacro de outrem: ocorre a partir da construção da figura modal de outrem como parceiro-sujeito no plano cognitivo (Landowski, 1992), por meio de informações e conhecimentos prévios sobre ele (Baldissera, 2001), pois nos encontramos imersos em mercados de conversações (Pérez, 2012), isto é, em imensos arquivos de modos de vida (Bruno, 2012).

Em terceiro, a construção da situação de referência: ocorre por meio das relações de poder materializadas por meio do discurso entre os sujeitos individuais e/ou coletivos. Portanto, a estratégia é compreendida no plano das enunciações, que se encontram sobre bases comuns e que possibilitam a identificação das diferenças das singularidades (Landowski, 1992). Em um contexto direcionado aos estudos da comunicação organizacional, esse fato implica na estratégia como processo de construção e disputa de sentidos (Baldissera, 2001) em estado contínuo, pois passa a ser o lugar do encontro das diferenças (Pérez, 2012).

Em quarto lugar, o fazer estratégico: ocorre a partir da perspectiva profissional do estrategista, que visa à produção de um fazer e/ou transformação de um estado (Landowski, 1992). Esse estrategista é reconhecido no contexto comunicacional e, portanto, representado pelo profissional de relações públicas na articulação dos recursos comunicacionais digitais (Baldissera, 2001) e como interlocutor e articulador de estratégias (Pérez, 2012);

Em quinto lugar, as táticas enuncivas e estratégias enunciativas: se dão pela articulação entre o ato enuncivo com o discurso enunciado (Landowski, 1992). No ato enuncivo a partir do precisar, escolher e beneficiar-se (Baldissera, 2001) relativos à sociotécnica particular do medium digital e considerado no agir para o futuro/antecipação e escolha de métodos/formas desse agir em detrimento de outros(as) (Pérez, 2001). Já o discurso enunciado ocorre a partir 
da escolha e potencialização (Baldissera, 2001) dos processos comunicacionais. Por meio dessa dinâmica definem-se os estilos/formas dos sujeitos individuais e coletivos frente ao ambiente (Pérez, 2001); ou seja, o jeito próprio/particular de perceber, fazer e se posicionar nas ambiências digitais como mediação estratégica comunicacional.

A visualização e análise das ações nos meios digitais, no contexto em que se dão as estratégias, constituem-se na articulação entre: o ato enuncivo (o fazer/existir/representar) que ocorre por meio da sociotécnica particular às ambiências digitais; com o discurso enunciado (saber dizer/publicizar) que ocorre a partir de três dimensões do processo comunicacional acionado através do Link Contextual de Referência a Outrem (LCRO) 5 .

Por sua vez, o Link Referencial de Referência a Outrem nutre, em sua composição, o processo comunicacional (sócio-técnico-discursivo) quando analisado sob o prisma das três dimensões propostas por Vizer (2011): Referencial, ou seja, que se refere ao dispositivo de construção discursiva de "realidades", os "conteúdos" do que se "fala"; Inter-referencial, isto é, a construção de relacionamentos entre atores sociais, pois, quando se "fala", se "fala" com alguém; e Autorreferencial, ou seja, o processo sócio-subjetivo de auto-observação reflexiva e de apresentação de si mesmo na sociedade.

Essas três dimensões do processo comunicacional possibilitam a visualização de três movimentos estratégicos possíveis nos media digitais:

a) $O$ primeiro movimento refere-se à passagem do primeiro (10) referencial para o segundo $\left(2^{\circ}\right)$ inter-referencial, ou seja, demonstra a construção discursiva por meio da construção de relações. Quando o enunciador se apropria do ator, espaço e/ou texto do outro no seu discurso, para posteriori construir a relação com este outro por meio do link contextual de referência a outrem;

b) $\mathrm{O}$ segundo movimento $\left(2^{\circ}\right)$ refere-se ao inter-referencial, ou seja, à construção de relações. Quando o enunciador constrói uma rede a partir do link contextual de referência a outrem;

c) $O$ terceiro movimento refere-se à passagem do $1^{\circ}$ referencial para o $2^{\circ}$ inter-referencial e o $3^{\circ}$ autorreferencial, ou seja, considera a construção de si para os outros através da construção de relações a partir da construção discursiva. Quando o enunciador ancora seu discurso no dito de outro a partir da construção da relação com o link

5 O link é um elemento tecnológico responsável por "ligar" os nós (Cavalcante, 2010) e, assim, construir redes de informações; entretanto, também sociais (Lasta, 2015). 
contextual de referência a outrem para reafirmar sobre si mesmo ou contra argumentar.

Assim, o link considerado contextual possibilita a inter-relação do medium com outro medium: ao referenciar outros espaços (media), esse está construindo redes na web, logo se inter-relacionando com outros media; a inter-relação do ator com outro ator: ao referenciar um espaço, esse está referenciando outro ator social, logo se inter-relacionando com outro ator. Ator tece em torno do seu espaço (medium) uma rede de significados e relações; e a Reelaboração do discurso por meio do discurso de outrem: ao referenciar o dizer do outro, retirado do "espaço" original deste, rearticula no seu espaço.

Em síntese, o LCRO encontra-se "dentro" da estrutura do texto que, por sua vez, é possibilitado pelo programa e disposto no espaço das ambiências; portanto, ligado ao dizer da organização através de práticas estratégicas nos media digitais:

$1^{\circ}$. Introdução do discurso de outrem para contra argumentar: ocorre quando o enunciador constrói o enunciado a partir da inserção do discurso do outro, que está "falando" diretamente sobre ele no seu discurso com o uso de aspas. Baseia sua argumentação na desconstrução do discurso do outro para assim reconstruir o seu contra, argumentando;

$2^{\circ}$. Introdução do discurso de outrem para reafirmar: ocorre quando o enunciador constrói o enunciado a partir da inserção do discurso do outro, que está "falando" diretamente sobre ele, no seu discurso com o uso de aspas. Baseia sua argumentação na atribuição da responsabilidade pelas inferências ao outro para se reafirmar por meio deste outro;

3०. Introdução do discurso de outrem indiretamente para contra argumentar: ocorre quando o enunciador constrói o enunciado a partir da inserção do discurso do outro, que está "falando" diretamente sobre ele no seu discurso sem o uso das aspas. Baseia sua argumentação na desconstrução do discurso do outro para assim reconstruir o seu contra, argumentando;

40. Introdução do discurso de outrem indiretamente para reafirmar: ocorre quando o enunciador constrói o enunciado a partir da inserção do discurso do outro, que está "falando" diretamente sobre ele no seu discurso sem o uso das aspas. Baseia sua argumentação na atribuição da responsabilidade pelas inferências ao outro para se reafirmar por meio desse outro; 
$5^{\circ}$ Elaboração do discurso com inserção de outrem nele: ao referenciar o dizer do outro, retirado do "espaço" original desse, articula no seu espaço para: discurso elaborado a respeito de outrem: ocorre quando o enunciador constrói o enunciado sobre um determinado ator/ espaço e/ou texto e o utiliza na construção argumentativa;

$6^{\circ}$ Elaboração do discurso com inserção de outrem nele: ao referenciar o dizer do outro, retirado do "espaço" original desse, articula no seu espaço para: outrem utilizado como fonte: ocorre quando o enunciador constrói o enunciado sobre uma determinada temática e designa um ator/espaço e/ou texto como fonte daquela informação; $7^{\circ}$ Elaboração do discurso com inserção de outrem nele: ao referenciar o dizer do outro, retirado do "espaço" original desse, articula no seu espaço para: apoiado em outrem: ocorre quando o enunciador constrói o enunciado sobre uma determinada temática e utiliza um ator/espaço e/ou texto para dar suporte argumentativo;

$8^{\circ}$ Encaminhamento do enunciatário para o ator/espaço/conteúdo pré-selecionados: ao referenciar um ator, espaço e/ou texto está também conduzindo o enunciatário para outros espaços (media) e/ou textos pré-determinados de forma: direta: ocorre quando o enunciador estimula o enunciatário a "ir" para aquele ator, espaço e/ ou texto;

$9^{\circ}$ Encaminhamento do enunciatário para o ator/espaço/conteúdo pré-selecionados: ao referenciar um ator, espaço e/ou texto está também conduzindo o enunciatário para outros espaços (media) e/ou textos pré-determinados de forma: indireta: ocorre quando o enunciador não instiga o enunciatário a "ir" para um determinado ator, espaço e/ou texto.

Desse modo, as possíveis práticas são estabelecidas através de outrem e/ ou de seu dizer (ator/espaço/conteúdo) para construir o dizer da organização, portanto, experiência da organização em composição com a experiência do outro/outrem. Ou seja, considerando os pressupostos de Barichello (2014), quando afirma que as ambiências digitais permeiam a sociedade e passam a afetar tanto as instituições e organizações como os indivíduos em suas relações, portanto, (re)configuram as interações, uma vez que esses processos comunicacionais interferem nas lógicas pelas quais as organizações se comunicam, se constituem e se legitimam. 
Ensino teórico-prático da práxis das relações públicas em ambiências digitais

Esta proposta está ancorada na área das relações públicas considerando sua função política organizacional (Simões, 1995, 2001), isto é, as relações de poder entre organização e seus públicos. Assim, supõe que devemos realizar constantes análises das situações e, caso necessário, propor outros quadros de referência, tanto para o ensino como para a prática de sua atividade. Logo, o entender e o praticar a atividade profissional de relações públicas está implicado tanto nas formulações teóricas como em uma definição da atividade, que integra os aspectos conceituais (teóricos) com os operacionais (práticos).

A base relacional da proposta nos encaminha à práxis, que considera a unidade entre teoria e prática. Utiliza a noção de práxis deVázquez (1968), ou seja, a partir da relação indissolúvel entre a prática e a teoria, e vice-versa. Tipificar a práxis como reflexiva remete a um nível no qual a consciência, ao tomar o centro de cena no processo de realização de objetivos, nos encaminha para a seguinte dinâmica: o subjetivo que se objetiva e o objetivo que se subjetiviza. Portanto, a atividade prática em nível de práxis reflexiva obedece a um objetivo prévio traçado, enquanto que o seu resultado tratará da objetivação do sujeito prático (individual ou coletivo), ocorrendo adequações entre objetivos e resultados.

Em síntese, essas considerações nos permitem rearticular a teoria de relações públicas e suas atividades práticas no contexto relacionado à sociedade midiatizada e, assim, propor a esquematização deste processo, conforme apresentado no Quadro 1:

Quadro 1 - Atividade de relações públicas nos media digitais a partir da reinterpretação de Simões $(1995,2001)$

\begin{tabular}{|l|l|}
\hline Elementos & $\begin{array}{l}\text { Atividade de Relações Públicas na sociedade } \\
\text { midiatizada }\end{array}$ \\
\hline - Definição operacional & $\begin{array}{l}\text { - Diagnosticar > Pesquisar o sistema; } \\
\text { - Prognosticar > Prever sobre o sistema; } \\
\text { - Assessorar > Ter alternativas para/no sistema; } \\
\text { - Implementar > Planejar e executar sobre/no sistema. }\end{array}$ \\
\hline
\end{tabular}




\begin{tabular}{|c|c|}
\hline $\begin{array}{l}\text { - Objetos da ciência } \\
\text { e da atividade/ } \\
\text { corpo de análise e } \\
\text { de intervenção da } \\
\text { atividade: }\end{array}$ & $\begin{array}{l}\text { - Material: sistema organização-públicos no/pelo } \\
\text { medium digital; } \\
\text { - Formal: conflito/cooperação/ negociação. }\end{array}$ \\
\hline $\begin{array}{l}\text { - Causa da existência } \\
\text { da atividade: }\end{array}$ & - Iminência do conflito e/ou cooperação no sistema. \\
\hline - Aspecto político: & $\begin{array}{l}\text { - Ético-político-estético (legitimação-relação- } \\
\text { comunicação). }\end{array}$ \\
\hline $\begin{array}{l}\text { - Matéria-prima } \\
\text { (elemento comum às } \\
\text { bases de poder que } \\
\text { organiza o processo): }\end{array}$ & - Dados, informações, conhecimentos. \\
\hline $\begin{array}{l}\text { - Instrumentos de } \\
\text { busca e envio de } \\
\text { mensagens/técnicas } \\
\text { midiáticas: }\end{array}$ & - Media digitais (com estrutura "aberta" na Web). \\
\hline $\begin{array}{l}\text { - Objetivo da função } \\
\text { e da atividade/ } \\
\text { atividade: }\end{array}$ & $\begin{array}{l}\text { - Explicar/justificar a existência; as decisões; e as ações } \\
\text { da organização através da negociação nos processos } \\
\text { comunicacionais reconhecendo o outro para a } \\
\text { consecução da missão organizacional. }\end{array}$ \\
\hline $\begin{array}{l}\text { - Bases filosóficas } \\
\text { (que fatores } \\
\text { justificam a existência } \\
\text { da atividade): }\end{array}$ & $\begin{array}{l}\text { - Ética + estética (a legitimação através dos processos } \\
\text { comunicacionais nos media digitais). }\end{array}$ \\
\hline
\end{tabular}

Fonte: Lasta (2015, p. 105)

Prosseguindo a argumentação, sustentamos que o ensino teóricoprático de relações públicas é articulado em função de um processo e de um programa. No processo há o fenômeno em si (sociedade midiatizada) com todo 
seu entorno; no programa a formação de políticas definidas após a análise do processo. No processo estão alocados os objetos: a organização e os públicos nas/pelas ambiências digitais, onde se estuda o estado do sistema (cooperação e/ou conflito). Já no programa há a ação consciente e intencional de intervenção pelo profissional no processo, para mantê-lo ou redirecioná-lo, a partir de quatro práticas ordenadas logicamente por Simões (1995, 2001): $1^{\circ}$ ) diagnosticar; $2^{\circ}$ ) prognosticar; $3^{\circ}$ ) assessorar; e $4^{\circ}$ ) implementar.

Para dar suporte à argumentação desta proposta, trazemos os pressupostos de Vizer (2011) para compreender a questão da construção da teoria (conhecimento) sobre o próprio processo de transformação social (práxis). Esse processo associa a ação com a reflexão e a teoria com a prática, pois, a práxis requer reflexão sobre: a) a própria natureza da ação; b) as consequências dessa ação; e c) o contexto no qual se realiza essa ação.

Por conseguinte, a reflexão para transformar o conhecimento dos futuros profissionais de relações públicas, visa justificar suas ações no futuro, ou seja, pensar a práxis das relações públicas por meio da reflexão, considerando a teoria somada à prática como mediação estratégica comunicacional nas interrelações entre os múltiplos atores sociais.

As relações entre a empiria, a teoria como produção de conhecimento e as condições em que a prática se desenvolve encaminham para a pesquisa empírica em comunicação, ao ponderar a íntima relação entre a teoria e o empírico, operacionalizada por um dispositivo teórico-metodológico que descreve as cinco etapas do processo: nível relacional; nível vinculativo; nível da análise dos enunciados; nível crítico cognitivo;

Primeira etapa (nível relacional): corresponde à ação dos sujeitos em realizar contatos materializados na retórica por meio de dispositivos tecnológicos de comunicação (Sodré, 2007). Nesse nível, ocorre a descrição utilizando-se o método da observação aberta e não participativa (Johnson, 2010) dos agenciamentos dos atores com as ambiências (compreendidas como dispositivo tecnológico de comunicação) que entram em relação e/ou vínculo (realizam contatos) com outros múltiplos atores sociais, por meio da apropriação/uso dos LCRO (materialização da retórica). Essa etapa é organizada após delimitação do campo de estudo.

Segunda etapa (nível vinculativo): corresponde à montagem da lógica por meio da análise estrutural das redes sociais (Lemieux; Ouimet, 2004), isto é, a lógica implicada no lugar social das interações intersubjetivas dos múltiplos atores que estão agenciados com essa ambiência. Logo, o ator está exteriorizado nesse espaço, que lhe pressiona para fora de si e o divide, ao se relacionar com os 
demais múltiplos atores (ao fazer uso do LCRO sua exterioridade está posta em relação com este outrem, que o divide entre o individual e o social). Essa etapa somente é possível depois da execução da primeira. Entretanto, deixa de lado as relações entre as proposições dos múltiplos atores (organizações discursivas) que o método subsequente abrange.

Já, a terceira etapa acrescenta o método da análise dos enunciados (Peruzzolo, 2004), isto é, da organização do discurso dos múltiplos atores, pois o discurso "fala" para "alguém", busca o outro - relacionamento intersubjetivo -, ele não é texto nem fala; trata-se da relação dos sujeitos no texto e na fala. E nessa análise a relação intersubjetiva dos sujeitos e os efeitos de sentido (modalidades do dizer) são apreendidos para que se possa chegar à última etapa. E, essa etapa, somente é possível depois que a segunda for cumprida.

Quarta etapa (nível crítico-cognitivo): corresponde à redescrição do modo de ser dos atores no contexto da sociedade midiatizada. Ela nos encaminha à imbricação entre as etapas 1, 2 e 3, ou seja, a apreensão dos agenciamentos dos atores com as ambiências digitais considerando seus aspectos tecnológicos (espaço/programa/texto). Ou seja, apreende a retórica materializada, somada às relações intersubjetivas, que resulta nos processos comunicacionais digitais.

Considerando essas prerrogativas, prospectamos, a partir da visualização da figura 1, o seguinte raciocínio para o processo do ensino acerca da práxis reflexiva das relações públicas: identificação do objeto, exame crítico das práticas, busca de explicações alternativas; experimentação de modos alternativos de se fazer; revisão das estratégias empregadas e realização de novas experiências e reflexões.

Figura 1. Processo de reflexão sobre a práxis das relações públicas

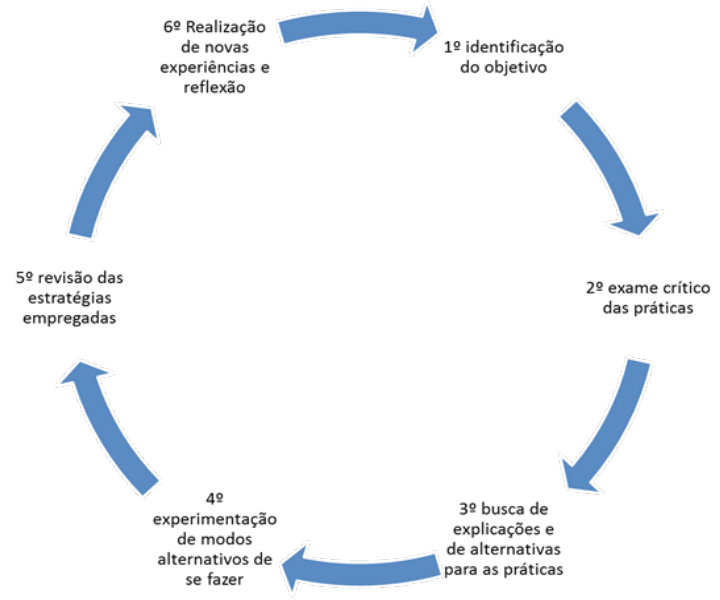

Fonte: Lasta (2015, p.110). 
A figura 1 apresenta uma proposta baseada em seis processos dependentes e sob um ciclo recursivo, pois o contexto para o ensino das relações públicas, ao estar fundamentado na sociedade midiatizada, nos atribui considerarmos a dinamicidade envolta a essa conjuntura. Isto é, o ensino de relações públicas em ambientes digitais requer reflexão constante acerca tanto da teoria como das práticas, possibilitando a ampliação do conhecimento de forma contínua no espaço da universidade para este curso e para a profissão. A partir da sua visualização é possível intuir a seguinte racionalidade para o processo a ser aplicado junto aos futuros profissionais:

$1^{\circ}$ - Identificação do objetivo: nesta etapa do ciclo o futuro profissional terá de tomar consciência dos pressupostos relativos ao justificar e/ou explicar a existência, as decisões e as ações da organização por meio dos processos comunicacionais nos/pelos media digitais, reconhecendo o outro na relação (negociação).

$2^{\circ}$ - Exame crítico das práticas das relações públicas no contexto da sociedade midiatizada: neste item do processo caberá ao futuro profissional refletir e executar sobre as quatro práticas que ocorrem em nível empírico, relativas às atividades de relações públicas, dispostas na figura 2: 
- Figura 2. Exame crítico sobre a práxis das relações públicas no contexto da sociedade midiatizada ${ }^{6}$

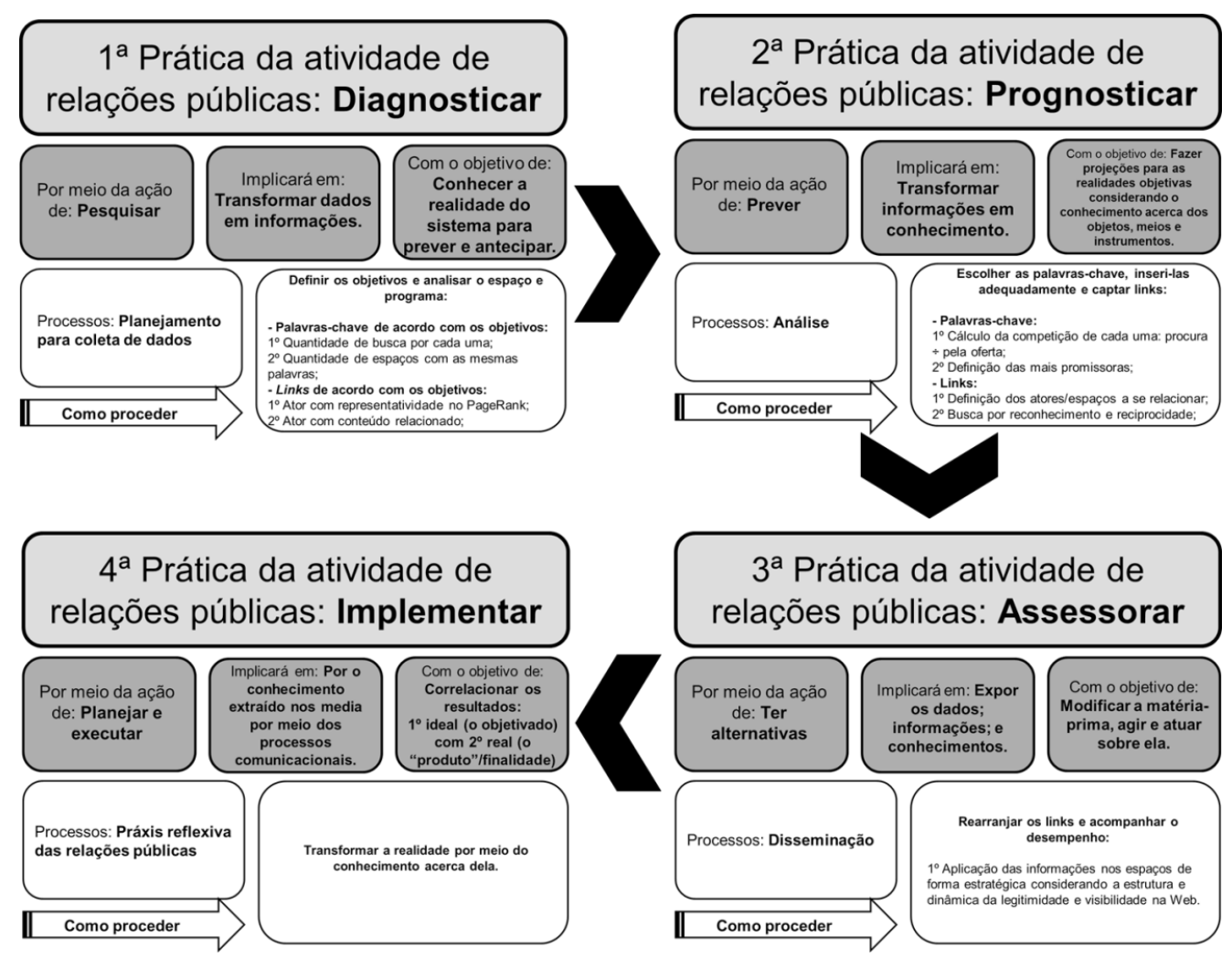

Fonte: as autoras

30 - Busca de explicações e de alternativas para as práticas: neste item do processo caberá ao futuro profissional tomar consciência a partir do constructo da figura 3 para arquitetar a estratégia comunicacional considerando o explicar e alternar das práticas:

6 Baseado no Quadro 10: Exame crítico sobre a práxis das relações públicas no contexto da sociedade midiatizada (Lasta, 2015, p. 243). 


\section{Figura 3. Construção da estratégia comunicacional}

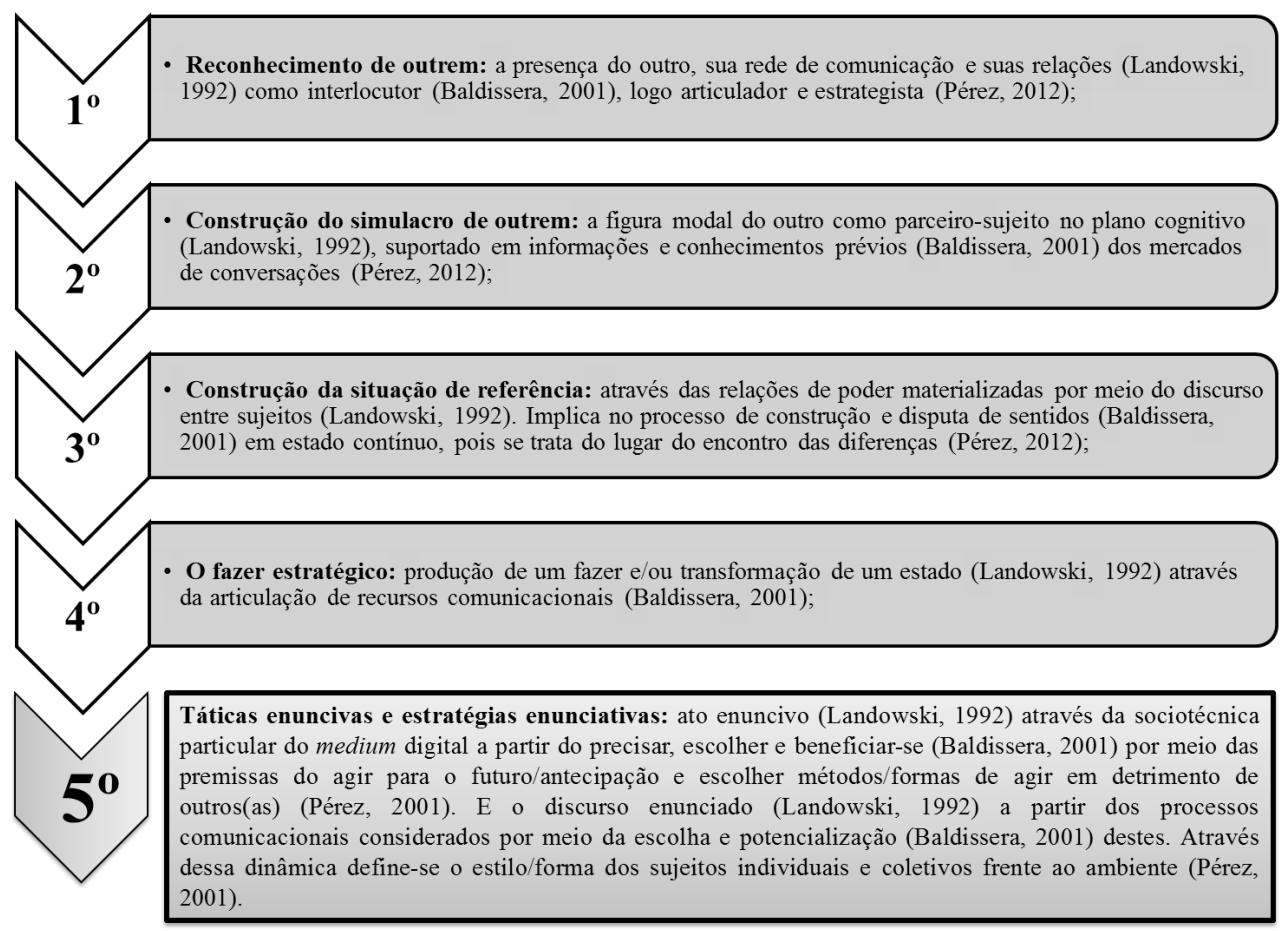

Fonte: as autoras.

Como a proposta está baseada no fenômeno da sociedade midiatizada, e essa ocorre por meio das explicações e/ou justificações das decisões e/ou ações das organizações pelas ambiências digitais, consequentemente impele ao futuro profissional considerar os processos comunicacionais. Entretanto, o estudante precisará de um passo anterior à efetivação do processo comunicacional, isto é, carecerá de construir a estratégia comunicacional que está contida nos cinco passos da figura 3. Contudo, somente será possível se antes tiverem sido executadas as quatro práticas das relações públicas, contidas na figura 2, pois essa dinâmica possibilita transformar a realidade (fenômeno) por meio do conhecimento adquirido com as práticas. A partir dessas ponderações da terceira etapa, contidas na figura 3, apreendemos os atores, as ambiências e os modos de atuação para a próxima etapa.

\section{$4^{\circ}$ - Experimentação de modos alternativos de se fazer (prática):} caberá ao futuro profissional experimentar os imbricamentos possíveis entre os movimentos das três dimensões dos processos comunicacionais e as práticas nas ambiências digitais. A seguir, na figura 4, são expostas as possibilidades de inter-relações entre os processos comunicacionais e as práticas de relações públicas: 
Figura 4: Processos comunicacionais e práticas de relações públicas

\begin{tabular}{|c|c|c|}
\hline $\begin{array}{l}\text { Processo Comunicacional: } \\
\mathbf{1}^{\circ} \text { Referencialidade } \rightarrow \mathbf{2}^{\circ} \text { Inter-referencialidade } \\
\text { "Conteúdos do que se fala"; } \rightarrow \text { Vizer (2011) } \\
\text { "Realidade exterior" }\end{array}$ & $\begin{array}{l}\text { Processo Comunicacional: } \\
2^{\circ} \text { Inter-referencialidade (imprescindível) } \\
\text { "Construção de relações } \rightarrow \text { Vizer (2011) } \\
\text { e/ou vínculos" }\end{array}$ & $\begin{array}{c}\text { Processo Comunicacional: } \\
1^{\circ} \text { Referencialidade } \rightarrow \mathbf{2}^{\circ} \text { Inter- } \\
\text { referencialidade } \rightarrow \mathbf{3}^{\circ} \text { Autorreferencialidade } \\
\text { "Processo sóciosubjetivo de } \rightarrow \text { Vizer (2011) } \\
\text { apresentação de si mesmo aos outros" }\end{array}$ \\
\hline LCRO para ator/espaço/conteúdo & LCRO para ator/espaço/conteúdo & LCRO para ator/espaço/conteúdo \\
\hline $\begin{array}{l}\text { informação; } \\
3^{\circ} \text {. Apoiado em outro: ocorre quando os temas } \\
\text { periféricos apoiam o tema núcleo, ou seja, o } \\
\text { tema núcleo não se refere a este outro, mas este } \\
\text { o apoia. }\end{array}$ & $\begin{array}{l}\text { Encaminhamento do enunciatário para } \\
\text { ator/espaço/conteúdo pré-selecionado de } \\
\text { forma direta ou indiretamente: } \\
1^{\circ} \text {. Diretamente: ocorre quando o enunciador } \\
\text { incita diretamente o enunciatário a "ir" para } \\
\text { outro ator/espaço/conteúdo. } \\
2^{\circ} \text { Indiretamente: ocorre quando o enunciador } \\
\text { não incita o enunciatário a "ir" para outro } \\
\text { ator/espaço/conteúdo. }\end{array}$ & $\begin{array}{l}2^{\circ} \text {. Introdução do discurso do outro diretamente (com uso de } \\
\text { aspas) para reafirmar: se explica e se justifica por meio } \\
\text { desse dito atribuindo a responsabilidade pelas inferências ao } \\
\text { outro, entretanto está se reafirmando através deste outro; } \\
3^{\circ} \text { Introdução do discurso do outro indiretamente (sem uso } \\
\text { de aspas) para contra argumentar: constrói sua } \\
\text { argumentação baseada na desconstrução do discurso deste } \\
\text { outro para contra argumentá-lo e, assim se explicar e se } \\
\text { justificar. } \\
4^{\circ} \text { Introdução do discurso do outro indiretamente (sem uso } \\
\text { de aspas) para reafirmar: explicar e se justificar por meio } \\
\text { desse dito atribuindo a responsabilidade pelas inferências ao } \\
\text { outro, entretanto está se reafirmando através deste outro. }\end{array}$ \\
\hline
\end{tabular}

Fonte: as autoras.

Após as demais etapas desse processo de reflexão sobre a práxis das relações públicas, adentramos na quarta etapa, que nos permite visualizar os possíveis processos comunicacionais e suas respectivas práticas. Logo, a figura 4 funciona como uma espécie de "mapa" para o futuro profissional por em experimentação os processos comunicacionais com suas respectivas práticas. Consequentemente, experimentando modos alternativos de se fazer a práxis de relações públicas no contexto digital.

$5^{\circ}$ - Revisão das estratégias empregadas: este item consiste em o futuro profissional identificar e aplicar a proposta da figura 4 e, a partir dessa ação, revisar continuamente os processos comunicacionais e as práticas empreendidas nas ambiências digitais. $E$, se necessário, por meio da figura 3, propor outra estratégia comunicacional que consequentemente alterará as experimentações contidas na figura 4. É importante salientar que essas inter-relações da figura 4 já foram reconhecidas no estudo empírico a partir da metodologia descrita anteriormente, portanto, essa figura 4 estabelece os processos e práticas já executados e reconhecidos. Contudo, não devemos nos limitar a essas inter-relações, e sim, a partir da figura 4, o futuro profissional poderá ampliá-las. 
$6^{\circ}$ - Realização de novas experiências e reflexão: este item remete à contínua experimentação e reflexão acerca desta proposta pelos futuros profissionais ao executarem este ciclo.

Neste raciocínio existe a compreensão de que novos conhecimentos podem cumprir a função de alimentar novas hipóteses e essas, por sua vez, podem promover o desenvolvimento de novas inquietações e investigações na área das relações públicas no âmbito digital. A unificação da teoria no ensino e a prática da atividade a partir do contexto do sistema organização-públicos busca trazer alto nível de consciência nos atos do processo ao antecipar o que se quer obter (resultado ideal) e a posteriori o que se obtém (resultado real). Todavia, para que esse processo ocorra, há que se ter conhecimento acerca do objeto, dos meios e dos instrumentos. Pois, o cerne da práxis das relações públicas se encontra na legitimação, na relação e nos processos comunicacionais.

A práxis reflexiva das relações, vista pelo ângulo proposto, resulta de uma (re)visão crítica a respeito da teoria e da prática. Esse processo argumentativo sugere a indissolubilidade entre teoria e prática, considerando a sua íntima unidade, posições relativas, autonomia e dependência de uma em relação à outra.

\section{Conclusões}

$\mathrm{Na}$ sociedade midiatizada os múltiplos atores sociais se constituem por meio dos agenciamentos com dispositivos sociotécnicos em ambiências digitais (dimensão individual) e, consequentemente, constroem matrizes sociais (dimensão relacional). Na primeira dimensão estão o fazer/existir/representar dos atores; na segunda, o saber dizer/publicizar pelo processo sócio-técnicodiscursivo. Portanto, a dimensão individual e a dimensão relacional sustentamse na mediação comunicacional, ou seja, consideram as ambiências digitais, os atores envolvidos e seus modos de atuação a partir do reconhecimento do outro. Consequentemente, a razão de ser (rationale) da área das relações públicas está nos relacionamentos que a organização aciona com atores coletivos e individuais e nos relacionamentos entre atores individuais e coletivos que seus públicos de interesse também acionam. A constatação dessa dinâmica comunicativa requer o (re)pensar acerca do agenciamento das organizações nas ambiências digitais, no seu dizer/publicizar, reconhecendo o valor social do outro.

Esta proposta permite que o processo das relações públicas seja compreendido por meio da teoria aliada à empiria, em um ciclo recursivo ou em espiral. Este entendimento acerca da práxis reflexiva das relações públicas considera o uso/apropriação das ambiências digitais como mediação estratégica comunicacional para com os múltiplos atores sociais e pode ser verticalizada nas 
discussões em torno do fenômeno comunicacional organizacional na sociedade midiatizada. Ou seja, buscamos com esta proposta ampliar as discussões sobre o ensino das relações públicas no contexto em que emergem outros modos de perceber, experienciar e conhecer diferentes formas contemporâneas de construção da realidade, nas quais o processo de midiatização constitui o fazer, o existir e a representação dos atores nos e por os media digitais.

\section{REFERÊNCIAS}

BALDISSERA, Rudimar. Estratégia, comunicação e Relações Públicas. Anais do XXIV Congresso Brasileiro da Comunicação. Campo Grande /MS, p. 1-11, 2001.

BARICHELLO, Eugenia. Midiatização e cultura nas organizações da contemporaneidade: o processo de midiatização como matriz de práticas sociais. In: MARCHIORI, M. (Org.). Contexto organizacional midiatizado. São Paulo; Rio de Janeiro: Difusão; Senac, p. 37-43, 2014.

BRAGA, José Luiz. Circuitos versus campos sociais. In: JUNIOR, J.; MATTOS, M.; Jacks, N. (org.). Mediação \& Midiatização. Salvador: EDUFBA; Brasília: Compós, p. 31-52, 2012.

BRUNO, Fernanda. Rastros digitais: o que eles se tornam quando vistos sob a perspectiva da teoria ator-rede? Anais do XXI Encontro da Compós. Juiz de Fora, jun., p. $1-18,2012$.

DOMINGUES, José António. O paradigma mediológico: Debray depois de McLuhan. Covilhã: Livros Labcom, 2010.

FELIPINI, Dailton. Google top 10: como colocar seu blog na primeira página do Google. Rio de Janeiro: Brasport, 2010.

HJARVARD, Stig. Midiatização: teorizando a mídia como agente de mudança social e cultural. Matrizes, São Paulo, p. 53-91, 2012.

JOHNSON, Telma.Pesquisa social mediada por computador: questões, metodologias e técnicas qualitativas. Rio de Janeiro: E-papers, 2010.

LANDOWSKI, Eric. A sociedade refletida: ensaios de sociossemiótica. São Paulo: Pontes, 1992.

LASTA, Elisangela. A práxis reflexiva das relações públicas na sociedade midiatizada: mediação estratégica comunicacional nos blogs corporativos. Tese (Doutorado em Comunicação) - Programa de Pós-graduação em Comunicação, Universidade Federal de Santa Maria, Santa Maria, 2015. 
LEMIEUX, Vincent; OUIMET, Mathieu. Análise estrutural das redes sociais. Lisboa: Instituto Piaget, 2004.

OLIVEIRA, José. Busca inteligente na Web: um guia para tornar sua busca na Web eficaz e rápida. Porto Alegre: Instituto de informática/UFRGS, 2010.

PÉREZ, Rafael. Las dimensiones de la estrategia. In: PÉREZ, R. Estrategias de comunicación. Barcelona: Ariel, p. 139-65, 2001.

Seminário avançado em comunicação estratégica organizacional. (anotações de seminário). Porto Alegre: PUCRS, 2012.

PERUZZOLO, Adair Caetano. Elementos da semiótica da comunicação: quando aprender é fazer. Bauru/SP: EDUSC, 2004.

RICOEUR, Paul. Percurso do reconhecimento. São Paulo: Edições Loyola, 2006.

SIMÕES, Roberto. Relações públicas e micropolítica. São Paulo: Summus, 2001.

Relações Públicas: função política. São Paulo: Summus, 1995.

SODRÉ, Muniz. Antropológica do espelho: uma teoria da comunicação linear e em rede. Petrópolis: Vozes, 2009.

Sobre a episteme comunicacional. Matrizes, São Paulo: ECA/USP, p. 15-26, 2007.

VÁZQUEZ, Adolfo. Filosofia da praxis. Rio de Janeiro: Paz e Terra, 1968.

VIZER, Eduardo. A trama (in) visível da vida social: comunicação, sentido e realidade. Porto Alegre: Sulina, 2011.

Recebido em: 26/9/2016

Aceito em: 3/11/2016

Endereço das autoras:

Elisangela Lasta <elisangela.lasta@gmail.com>

Universidade Federal do Rio Grande do Sul (UFRGS)

Faculdade de Biblioteconomia e Comunicação

Rua Ramiro Barcelos, 2.705 - Bairro Santana

90035-007 - Porto Alegre (RS) - Brasil

Eugenia Maria Mariano da Rocha Barichello <eugeniabarichello@gmail.com>

Universidade Federal de Santa Maria (UFSM)

Programa de Pós-Graduação em Comunicação

Avenida Roraima, 1.000 - Prédio 21 - Campus Universitário

97105-900 - Santa Maria (RS) - Brasil 